\title{
Interdisciplinarity: Suffering from a Lack of Effective Marketing?
}

\author{
Leslie J Wardley ${ }^{1}$ \& Charles H Bélanger ${ }^{2}$ \\ ${ }^{1}$ Assistant Professor, Shannon School of Business, Cape Breton University, Canada \\ ${ }^{2}$ Professor of Management, Faculty of Management, Laurentian University, Canada \\ Correspondence: Leslie J Wardley, Assistant Professor, Shannon School of Business, Cape Breton University, \\ Canada. E-mail: Leslie_Wardley@cbu.ca
}

Received: August 11, 2015

Accepted: August 28, 2015

Online Published: September 8, 2015

doi:10.5430/ijhe.v4n4p45

URL: http://dx.doi.org/10.5430/ijhe.v4n4p45

\begin{abstract}
After a lulled period there is renewed debate in first-world institutions for increasing interdisciplinary studies and research. The literature has occasionally attempted to capture what "true interdisciplinary work" was and to lure the unbelievers with the use of metaphors, fables, and stories that has led to confusion. As a result, interdisciplinarity is not well understood and the lack of message clarity impacts its standing within the industry and society in general. This paper purports to overcome marketing communications barriers by: a) defining and positioning the interdisciplinary movement vis-a-vis more traditional approaches; b) explaining what it is and what it is not; c) examining whether interdisciplinarity is on its way of becoming an established discipline; and d) parting with some concluding remarks.
\end{abstract}

Keywords: Interdisciplinary, Marketing, Target market, Branding, Point of difference, University, Post-secondary, Communication channels, Communication strategy

\section{Introduction}

According to the American Marketing Association website, marketing can be defined as "the activity, set of institutions, and processes for creating, communicating, delivering, and exchanging offerings that have value for customers, clients, partners, and society at large." Annually, universities spend significant portions of their budgets attempting to attract new students, to retain current students and build reputational/brand awareness to gain a point of difference (POD) within the industry. Thus, the methods used by universities to communicate and deliver their value exchange efforts to their stakeholders fall within an overall marketing context.

Similar to business enterprises, non-profit organizations and their marketing administrators understand the importance of developing effective communications through: 1) identifying the target audience, 2) setting objectives, 3) designing communication strategy and 4) selecting communication channels. The message conveyed and the money allocated to developing strategic marketing plans impact each faculty and department. So what happens when there is confusion with the marketing message and/or the classification of the product not only with the target audience but also within the industry?

"Interdisplinarity" is making a comeback after having been introduced in the 1970 s in many higher education institutions as a solution to meet new socio-economic realities such as financial constraints, expansion of knowledge, and student demand for more relevance (Baum, 1975; Doyal, 1974; Harvard's Report, 1978; Heaney, 1976; Pickar, 1970; Strauss, 1973; Swora \& Morrison, 1974). After a lulled period that saw early hard-core activists such as Klein (1990) and Newell $(1992,1983)$ among a few others continue to stir the fire of the movement, there exists a renewed debate in first-world institutions for increasing interdisciplinary studies and research.

This resurgence is manifested by more so-called interdisciplinary programmes, job postings asking for this span, more government funding and requests from community leaders, and more admonitions to break the perceived silos of academic disciplines (Jacobi, Jahn, Krawatzeck, Dinter, \& Lorenz, 2014; Krishnan, 2009). For example, according to the McKinsey Global Institute Report, up to 190,000 jobs demanding analytical skills that span several knowledge domains will be needed in the next five years (Jacobi et al., 2014). However, questions regarding the nature of interdisciplinarity and where it fits in the structure of universities remain largely unanswered. The use of this buzzword might evoke something new for younger scholars, but the fundamentals such as effective management of resources and knowledge management, have not changed. The literature has occasionally attempted to capture what 
"true interdisciplinary work" was and to lure the unbelievers with the use of metaphors, fables, and stories which has led to even more confusion (Wheeler \& Miller, 1970; Repko, 2008). As a result, interdisciplinarity is not well understood and the lack of message clarity impacts its standing within the industry and society in general.

This paper purports to overcome communications barriers by: a) defining and positioning the interdisciplinary movement vis-a-vis more traditional approaches; b) explaining what it is and what it is not; c) examining whether interdisciplinarity is on its way of becoming an established discipline; and d) parting with some concluding remarks.

\section{Disciplinarity}

A quick flashback to history informs us that ancient universities such as Alexandria, Padua, and Bologna had one discipline, Philosophy. Its purpose was to prepare medical doctors, religious leaders, science "men", lawyers, and civil servants. It was uncomplicated and unidimensional. The Kameralwissenschaften of the Humboldt University created a new university framework based on multi-functions and multi-disciplines. In contemporary times, disciplines are to academic institutions what taxes and death are to living; they are unavoidable.

According to Salter and Hearn (1997), disciplines can be defined as "recognizable communities of scholars", whose conduct is governed by conventions, technical language, particular objects and methods of analysis, and standards. This explanation is constructed based on being able to categorize scholars into groupings according to topics; from this grouping, methods and ways to approach analysis are developed. One sees that disciplinary study is viewed as a way to group members based on their specific pool of knowledge, idiosyncratic language and way of approaching problems. Similarly, Chandler (2009) described an academic discipline as, "involv[ing] styles of thought, that is, procedures for identifying and gathering evidence, ways of posing and sequencing questions, conventions for distinguishing productive and unproductive questions, and practices for establishing sound demonstrations, building arguments, citing authorities, or making cases" (p. 732). Unlike the previous reference that related to the separation of scholars or solidified boundaries, Chandler's (2009) definition is more procedurally driven with little attention paid to the participants. In his definition, more connections are made to the collection of evidence and the formation of questions with less focus placed on the development of groupings of theorists.

Interestingly, Newell (1992) did not define the word discipline; instead he chose to describe its participants in action. For this author, the way of approaching a topic, the questions they ask, the concepts and theories they formulate are more determinant than the conclusions they arrive at. Newell's focus is on the manner in which a topic is dissected; it is not focused on the end result so the actions and activities of theorists within academic disciplines also become entrenched in the definition.

Power and politics are included in Weingart and Stehr's (2000) description of disciplines as "not only intellectual but also social structures, organizations made up of human beings with vested interests based on time investments, acquired reputations and established social networks" (p. xi). This is encapsulated in statements by members of disciplines who typically identify and introduce themselves professionally as: "I am an economist", "I am a physicist", "I am a lawyer." They wish to indicate they belong to a particular type of training, professional associations, and work specializations.

Other scholars (Benson, 1998; Moran, 2010) refer to disciplines as an enclosed field or virtual space with its own hierarchies shaped by the struggle for academic capital exercised in a specific discipline. Benson uses words like contours, boundaries and guidance of internal standards of relevance in subject matter and method when describing the disciplines. Constraint and control are evidently part of defining this term based on the multiple references to enclosures. In short, disciplines are ways of categorizing activities and individuals who perform these activities within knowledge territories.

Beyond the differentiated semantics and angles used by various authors, Krishnan (2009) summarized the key ingredients that most disciplines possess: a particular object of research (e.g. law, society, politics), a body of accumulated specialist knowledge, theories and concepts that can organize the accumulated specialist knowledge effectively, specific research methods, a specific technical language, and institutional manifestation in the form of subjects taught at universities or colleges, respective academic departments and professional associations connected to it.

Learning about potential consumers of the product, current users and how the product fits within society are critical to developing effective marketing communications. Being able to define, classify and describe the discipline's key attributes and characteristics makes it easier to identify the target audience and select the proper message and communication channels. This search for message clarity has led to even more defined programs and offerings (e.g., the accounting, finance and human resource streams commonly found in business departments). Accrediting 
organizations' functions and requirements are already driving university programs and staffing. For example, if a university wants to target future accountants they can communicate through accounting association websites, have the association help structure course offerings to meet market demand and explore partnerships with accounting accrediting bodies that will help to build brand awareness by having courses reviewed and accessed by third parties for quality. However, if a program of study cannot be defined can it be effectively marketed?

\section{Interdisciplinarity}

In contrast to the consistency found in theorists' definition of disciplinary study, interdisciplinarity has been harder to corner using commonalities and concise wording. That leaves us with the question of what is interdisciplinary work. Although similar wording is often used, there is no universally accepted definition. As there is some confusion about the definition of interdiscipline, the search could begin by using a commonly used source for defining terms, the online Merriam-Webster dictionary. This website takes the term interdiscipline to its simplest form of "involving two or more academic, scientific, or artistic disciplines" (Interdisciplinary, 2015). Albeit rather vague, this definition appears to be a reasonable departure point - interdisciplinary work does include more than one academic focus.

Let us review three definitions put forth by proponents of the movement. Aboelela et al. (2007) undertook a systematic review of literature in education, business, and health care in their search for common threads. While carrying out this process, they examined 14 definitions of interdisciplinarity in 42 recognized interdisciplinary research publications. In addition, they interviewed 14 scholars and came up with this definition:

"Interdisciplinary research is any study or group of studies undertaken by scholars from two or more distinct scientific disciplines. The research is based upon a conceptual model that links or integrates theoretical frameworks from those disciplines, uses study design and methodology that is not limited to any one field, and requires the use of perspectives and skills of the involved disciplines throughout multiple phases of the research process" (p.341).

The National Academy of Sciences, National Academy of Engineering, and the Institute of Medicine of the National Academies (2015) provide this definition:

"Interdisciplinary research is a mode of research by teams or individuals that integrates information, data, techniques, tools, perspectives, concepts, and/or theories from two or more disciplines or bodies of specialized knowledge to advance fundamental understanding or to solve problems whose solutions are beyond the scope of a single discipline or field of research practice" (p.26).

Finally, Rhoten, BoixMansilla, Chun, and Klein, (2006) offer this definition of interdisciplinary education:

"Interdisciplinary education is a mode of curriculum design and instruction in which individual faculty or teams identify, evaluate, and integrate information, data, techniques, tools, perspectives, concepts, or theories from two or more disciplines or bodies of knowledge to advance students' capacity to understand issues, address problems, and create new approaches and solutions that extend beyond the scope of a single discipline or area of instruction" (p. 3).

From these previous definitions, it becomes clear that the mere side-by-side juxtaposition of two or more disciplinary approaches is not interdisciplinarity. There needs to be a combination of integration of perspectives and methodologies, a complex issue that exceeds the borders of a single discipline, and cognitive advancement that would not be possible through the lens of single disciplines. When compared to disciplinary criteria previously established, it stands to reason that the interdisciplinary bedrock does present some challenges. If someone were to introduce herself/himself professionally as "I am an interdisciplinarian", this statement might be confronted with a moment of silence, being interpreted as "Who are you exactly?" or worse "What do you think you are?" Even as a strong proponent of interdisciplinarity, Klein (2005) suggested that the nature of disciplines might not be well understood and delineated either by disciplinarians or interdisciplinarians. A few issues emerge from this simple observation. One is raised by Aram (2004) as to whether disciplines are frozen in time or whether they are capable of exerting synergies among themselves as their members are reflective of new scientific, social, and cultural realities. A second issue, which is derived from Aram's query was put forth by Hunt (1994) questioning who is going to decide where and when disciplinary boundaries are crossed, assuming disciplines are monolithic entities with identifiable demarcations. And finally, Krishnan (2009) is asking whether the artificial creation of an interdisciplinary approach with an admittedly vague methodology to tackle a complex problem has a better chance at transcending knowledge discovered through disciplines that "make a greater effort of understanding and appreciating each other's work without abandoning their own distinct identities... and reference points" (p.51).

Thus, interdisciplinarity involves disciplines but only as a resource for the reconstruction of the interdisciplinary 
findings into a new perspective. It is no wonder why so many people interpret the concept in so many different ways. This urge for the definition to include not only the expertise of the theorist but also the procedure for obtaining knowledge and the process of integration adds multiple layers to the explanation which can create confusion. It may also be a symptom of a fragile entity in search of an identity. So the questions become: should interdisciplinarity be marketed as something apart and separate from disciplines placing a focus on the point of difference (POD) as an effective marketing strategy or has interdisciplinarity become a discipline in its own right? There are certainly dangers to the use of POD at the university program offering level. Unlike trying to build brand awareness of the university in the hope it will attract new students, "undisciplining" interdisciplinarity could actually encourage more confusion about its benefits and fit within the marketplace. Identifying the right target audience requires some consistency in the offerings which adds another layer to the debate.

\section{Is Interdisciplinarity an Emerging Academic Field?}

Can interdisciplinarity gain more respect by becoming a discipline in itself? Although this question appears to be the ultimate antithesis to interdisciplinarity, there is some merit in exploring its standing as an academic field. As previously mentioned, disciplines have distinctive traits characterizing their adherents, the way they pursue knowledge and assess their activities (Shailer, 2005). Could this be applied to interdisciplinarity? Disciplines do involve specific viewpoints formulated by the focused academic study of relevant literature. This narrowing of focus is how practitioners of research (theorists) build expertise in their field of study. Technical language plays a role within the disciplines. This short-hand form of communication is based on insiders' knowledge of key concepts and theories from specific fields of study.

As academic journals are geared towards practitioners of these disciplines, it would be patronizing to reduce scientific terms and foundational theories to the level of an everyday reader. However, the inclusion of methodology can cause one to reflect about whether a discipline can be defined by the methods it uses? Many would be sympathetic to Chandler's critical essay entitled Introduction: Doctrines, Disciplines, Discourse, Departments (2009), in which he argues disciplines cannot be reduced to a method. To use methodology to define a discipline would be restricting researchers (within these fields of study) from developing a system of approach that best fits their needs. There are many ways to approach a problem. There are also methods that are included in more than one discipline. If a specific process or technique assists in the formation of a discipline, how does one determine which discipline could lay claim to these transitory methodological approaches? There are issues with defining a discipline by its methods of research because methods could be viewed as transient and mutate from one discipline and over time become entrenched in another discipline. For an in-depth analysis, Chandler's definition will be broken down into a few key points. He stated that a way to define a discipline is by: 1) specifying the procedures for gathering evidence, 2) identifying the correct research question(s), and 3) building the structure of the argument through studying specific viewpoints formulated by the academic study of relevant literature. If disciplines can be defined this way, it does not exclude interdisciplinarity from achieving the status of a discipline.

\subsection{Procedures for gathering evidence}

Let's take the first point of the definition that was used for disciplinary study, i.e., specifying the procedures for gathering evidence. This could also be used to describe interdisciplinary study. During interdisciplinary studies, hours are spent discussing how to approach interdisciplinary research. The Repko textbook (2008), as an example, includes detailed procedures for obtaining evidence among other defined procedures. A condition of interdisciplinarity is that it must span different bodies of literature; however, this could in itself be described as a specific process for gathering evidence.

\subsection{Identifying the correct research question(s)}

The second point regarding disciplinary study is identifying the correct research question(s). Klein's description of the process for achieving an integrative synthesis or interdisciplinary approach includes: " a) defining the problem, b) determining all knowledge needs, and c) developing an integrative framework and appropriate questions to be investigated" (1990, p. 188). As demonstrated by Klein, interdisciplinary study has also clear systems for defining this section of the research too. The need to identify the research focus influences how a research question is formulated and defined. This was not very different from a disciplinary approach that draws clear guidelines for formulating a research question which identifies the area of research focus by asking: "What am I doing? For what purpose am I doing it?... [as these] questions can help focus your efforts towards achieving your ultimate purpose for gathering data: to resolve the problem" (Leedy \& Ormrod, 2005, p. 47). 


\subsection{Integrated synthesis}

The third point included in the definition of interdisciplinarity is building the structure of the argument through studying specific viewpoints formulated by the study of relevant literature. Klein's description of the process for achieving an integrative synthesis or interdisciplinary approach also includes:

1. a) specifying particular studies to be undertaken, b) engaging in the "role negotiation", c) gathering all current knowledge and searching for new information, d) resolving disciplinary conflicts, and e) building and maintaining communication through integrative techniques;

2. a) collating all contributions and evaluating their adequacy, relevancy and adaptability, b) integrating the individual pieces to determine a pattern or mutual relatedness and relevancy, c) confirming or disconfirming the proposed solution (answer), and d) deciding about future management or disposition of the task/project/patient/curriculum (1990, p. 188).

Again, one does not find a contrast in how this requirement is fulfilled between disciplinary and interdisciplinary research. For disciplinary study, one must support the argument using relevant and current bodies of literature that help to build the argument. One must include citations from key bodies of literature and theorists within that area of study. However, in a practical sense, these bodies of literature may not fall neatly under the heading of a discipline as many different literatures are used when attempting to build the structure of an argument. Thus, any conflicts within these disciplines would need to be addressed. This is similar to interdisciplinary study that follows the same process; the only difference could be noted in the mandatory inclusion of citations that span various areas of literature or disciplinary viewpoints in order to confirm its interdisciplinary aspects. For both, there is a system for building the structure of the argument - this is not a haphazard process in disciplinary or interdisciplinary work.

\subsection{Recognized community of scholars}

Does this mean that interdisciplinary study could be at the point of becoming a discipline in itself? Some could argue that a definition was selected and through manipulation or lack of clarity in explaining the differences between the processes for gathering evidence, defining the research question(s) and building the structure of the argument there has been an attempt to draw parallels where none exists. Thus, one additional criterion will be added to the list that is found within Salter and Hearn's (1997) definition that was mentioned earlier: recognizable communities of scholars that develop conventions governing the conduct of research and its adjudication. Communities of scholars, depending on their referent power, can govern the formation of a discipline in many ways but let's focus on acknowledged literature, academic journals and conferences, research funding and academic departments.

Common authors and texts become part of the disciplining process. To support this premise, Repko (2006) suggests the use of textbooks is a vehicle for disciplining interdisciplinarity. He pointed out the textbooks highlight the similarities between the main interdisciplinary theorists causing a fusion (consensus) or operationalizing of the interdisciplinary research process. One cannot undertake the study of interdisciplinarity without learning the names of some of the main theorists such as Klein, Newell, Moran, Repko, Salter, Weingart and Shailer. Some of these authors have been involved in the exclusive examination of interdisciplinarity since the 1970s. With the resurgence of interdisciplinary study over the last decade, they have come to prominence once again. Their work has come to represent more than foundational texts, these bodies of literature have reached canon status by being viewed as the "sacred scripture" of interdisciplinary study. This reminds one of Moran's (2010) description of English's obtainment of "disciplinary coherence by focusing on certain clearly defined works" (p. 43). English gained its disciplinary status by "limiting [its] subject matter, when faced with the possibility that the broadness of its concerns might make it too amorphous and ill defined" (Moran, 2010, p. 42-43). One can see that interdisciplinary study is moving in the same direction with its "common books and authors" program of study.

\subsection{Academic journals, conferences, and funding}

Academic journals and conferences are established venues for presenting disciplinary findings. The stature of the academic journal or conference and the peer-review process add credibility to the theories contained on its pages and assist with the transmission of information concerning current research findings. In her chapter on the "Evolution of Interdisciplinarity", Klein (1990) discusses how the acceptance of the validity of a theory or argument is confirmed by the prestige of the journal where the discussion is printed. Lately there has also been an increase in interdisciplinary conferences with venues stretching across the globe such as the International Conference on Interdisciplinary Research and Development in ASEAN Universities supported by the Asian university association, the IWK Annual Interdisciplinary Research Conference, the Healthcare Interdisciplinary Research Conference and Student Colloquium (in its $14^{\text {th }}$ year), and the International Conference on Interdisciplinary Research Innovations (ICIRI) which promotes interdisciplinary research in education. Interdisciplinary study has crossed the threshold of an emerging discipline by 
having peer-reviewed academic journals and conferences which are specifically tied to interdisciplinary research. This has moved them forward in their academic standing.

Funding also plays a role in establishing a discipline as monetary contributions allow "scholars relief from teaching and administrative duties and a space in which to carry out their own work [research]" (Chandler, 2009, p. 738). Thus, it can be argued that funding, both internal and external to the university, can shape the types of research questions that are selected for further exploration. It would be naive to state that research is purely dictated by the spiritual pursuit of higher knowledge without any concern for accolades or needed financial support for research projects. Administrative and monetary support is needed to pursue a field of research. As noted by Shailer, "interest in interdisciplinarity comes from outside the university such as governments, granting agencies, foundations, industry and other stakeholders in the production of knowledge" (2005, p. 1). When filling out a (Canadian) Social Sciences and Humanities Research Council (SSHRC) application, students are offered the opportunity to select interdisciplinarity as an academic field of study. This means this particular field of specialization is recognized by funding agencies as a validated focus within the hierarchy of the university system.

Academic departments also become part of the disciplining process. As noted in Moran, "a discipline is, like any 'field', an enclosed space with its own hierarchies determined by the struggle for academic capital appropriate to that discipline" $(2010$, p. 67). If one notes the trend within universities and funding agencies, interdisciplinary study is starting to gain a hierarchy separate from the disciplines from which it may have been formed. This embracing of interdisciplinary programs is evident in Canadian universities such as Carleton, Waterloo, York and Ryerson that offer: "Cognitive Science programs, Women's Studies, and others such as Social and Political Thought, Management Studies, Public Policy and Administration" (Shailer, 2005, p. 4). However, not only has there been an increase over the past decade in interdisciplinary undergraduate programs, other universities are offering graduate level programs in Interdisciplinary Humanities, Human Studies and Rural and Northern Health. This could be seen as an acknowledgement from the academy that there will be a need for the holders of interdisciplinary Master and Ph.D. level credentials in teaching and research positions.

This section proposes that there is a consensus of understanding of what interdisciplinarity is, which does not preclude it from being included in the ranks of the established disciplines. The importance of the established texts, academic journals, conferences, funding and programs as representation of a growing community of interdisciplinary experts and literature has been discussed. For all of these reasons, it appears that interdisciplinarity within the theoretical environment is on its way to achieving disciplinary status and should be marketed that way.

So how does interdisciplinarity find its own place within academia? Cross-functional integration that focuses on problem-based education is needed in our current landscape of globalization, rapid technical advancements and the use of big data (large amounts of data from diverse sources). The study of interdisciplinarity or teaching the process involved in interdisciplinary research could be contained within a discipline and marketed as a problem-based curriculum. There may be a need to follow specific guidelines to ensure an integrative approach but the work is still interdisciplinary. One needs to look at the problem from many different viewpoints before the gap in the knowledge and ways to overcome this identified gap can be developed.

\section{Ongoing Issues with Marketing Interdisciplinarity}

A lack of message clarity and no marketing focus mean lost marketing opportunities and fewer insights into practical problems. This is why getting the right message is so important as universities cannot focus only on tightening their disciplinary focus often demanded by accreditation bodies while governments and society are funding and seeking broader skillsets and outcomes.

As mentioned in the introduction, it is important to begin with a clear idea of who your target market is as it influences the decision about what to say, how to say it, and where to share the message. One of the explanations for the current interest in interdisciplinarity is universities' desire to find a way to initiate new programs without generating concern at the government level about the duplication of offerings at universities. Using education as an example, governments have started to enforce caps restricting enrolment numbers to reduce the over saturation of these graduates in the market. By offering interdisciplinary programs in education, caps can be avoided. But targeting the oversaturated education arena, as a marketing strategy would be ill advised. A better approach would be to look at the untapped market needs. For example, with the advancement of technology there are significant changes to how we share and control information. Big data was mentioned earlier. Linking up multiple sources of information can isolate phenomena in new ways and offers a more holistic approach to data analysis. Skills needed to quickly analyze large amounts of data from diverse sources are interdisciplinary by nature and build demand for jobs throughout industry and governments. Focusing on these types of untapped markets is strategically important for universities and ultimately for society. 
Next, it is important to establish there is a need for the product before developing the marketing message. Finding out why there is a gap between what currently is offered and what is needed within the market would be the next step. Klein's 1990 book, Interdisciplinarity: History, Theory and Practice, explains the evolution of knowledge through the useful metaphor of the tree of knowledge. If one were to view the growth of knowledge as mimicking a tree in the beginning stages of development, there would be minimal branches on the tree. The trunk would hold most of the mass or fibrous content. Normally, the progression of evolution would keep the tree branches growing upwards upon its solid foundation but within the tree of knowledge, external influences can amend the natural development. Growth can be outward with limbs becoming too congested and heavy. As a result, the tree branches are in danger of not being properly attached to its foundation and snapping off, thus, no longer having a connection to the rest of the tree. Similarly, without a centralized base of fundamental knowledge, academics can become too narrow in their focus, straying too far from centralized knowledge.

The modern concept of interdisciplinarity is centered on the problem of knowledge; with the branching and spreading out of knowledge, can the university system maintain the outward pressure or will the branches become even more brachiated heavy and hazardous to the whole? The danger lies in multiple people working on the same problem without a connection or communication - duplicating research instead of advancing knowledge with no synthesis or expansion of thought across the branches of disciplines. When participating in developing answers to real-world problems, an educated person is one who has surveyed the disciplines and attempted to form synergy with the multiple perspectives by linking theoretical disciplinary learning with applied knowledge (Shailer, 2005).

\section{Conclusion}

The purpose of this paper was to explain how disciplinarity and interdisciplinarity had been defined by theorists, to position both concepts in the academic arena on overlapping and sometimes competing turf, and to discuss whether interdisciplinarity was in the process of acquiring the standing of a discipline. The "business case" evoked in the 1970s for encouraging the development of a space that would broaden a discipline's scope has become more sophisticated today since higher education has evolved into big business. Expansion of knowledge, financial constraints, and relevance (popularized by hippies) have been replaced by knowledge management, optimization of (expensive) resources, and supply and demand forces respectively, all business vernacular.

There is no question that the prevalence of interdisciplinary programs of studies and research continues to increase in universities to satisfy the landscape of a changing environment and the demands for academic packages that are attractive and marketable to a segment of the clientele.

However, it will take better message clarity about what defines interdisciplinary work and its advantages before universities are in a position to identify the potential target audiences, design communication strategies and select communication channels. Until that happens, these trends are not going to drive traditional disciplines out of business by any stretch of the imagination, but they are certainly prodding them to work at the cusp of their comfort zone or to make parent alliances if they want to continue to strive or to survive in some cases. The ultimate winner is the overall body of knowledge that keeps pushing the frontiers.

As for interdisciplinarity, it may be condemned to play the role of a "disciplinary" lever for establishing the foundations of new disciplines even though it is not the intent. The past offers many examples of bodies of knowledge with humble and interdisciplinary beginnings that grow, with time, into quite separate and disciplinary fields. For instance, let us mention Social work, Nursing, Bioethics, and Forensic Science. They all started by integrating elements of various disciplines and fields of study with no solid anchor to call their own. At some point, their development became strong enough and their training rigorous enough to call it a discipline, not seriously contested by other academic groupings.

Notwithstanding the previous paragraph, it is anticipated that much of the future interdisciplinary knowledge will develop within a discipline by extending their range of research and acting like scavengers towards weaker areas of knowledge. There seems to be little wrong with this as nature in general has been a resilient example of this model.

\section{References}

Aboelela, S.W., Larson, E., Bakken, S., Carrasquillo, O., Formicola, A., Glied, S., Haas, J., \& Gebbie. K. (2007). Defining interdisciplinary research: Conclusions from a critical review of the literature. Health Services Research, 42, 329-346. http://dx.doi.org/10.1111/j.1475-6773.2006.00621.x

Aram, J. (2004).Concepts of interdisciplinarity: Configurations of knowledge and action. Human Relations, 57(4), 379-412. http://dx.doi.org/10.1177/0018726704043893

Baum, J. (1975). Interdisciplinary studies, the latest experimental rage. College Composition and Communication, 26, 30-33. http://dx.doi.org/10.2307/356796 
Benson, T. C. (1982).Five arguments against interdisciplinary studies. Issues in Integrative Studies, 1, 38-48.

Chandler, J. (2009). Introduction: Doctrines, Disciplines, Discourse, Departments. The University of Chicago, p. 729 - 746. http://dx.doi.org/10.1086/599585

Doyal, L. (1974). Interdisciplinary studies in higher education. Universities Quarterly, $28,470-487$. http://dx.doi.org/10.1111/j.1468-2273.1974.tb00487.x

Harvard's Report on the core curriculum. (1978). The Chronicle of Higher Education, 16 (March 6), 15-19.

Heaney, R.P. (1976). Integration of health professions education. American Journal of Pharmaceutical Education, 39 , 440-445.

Hunt, L. (1994). The virtues of disciplinarity. Eighteenth Century Studies, 28(1), 1-7. http://dx.doi.org/10.2307/2739218

Interdisciplinary. (2015). In Merriam-Webster.com. Retrieved July 08, 2015, from http://www.merriam-webster.com/dictionary/interdisciplinary

Jacobi, F., Jahn, S., Krawatzeck, R., Dinter, B., \& Lorenz, A. (2014). Towards a design model for interdisciplinary information systems curriculum development as exemplified by big data analytics education. Twenty Second European Conference on Information Systems, Tel Aviv 2014, http://ecis2014.eu/E-poster/files/0825-file1.pdf [access July, 2015].

Klein, J. T. (1990). Interdisciplinarity: History, Theory and Practice. Detroit: Wayne State University Press.

Klein, J.T. (2005). Humanities, Culture and Interdisciplinarity/The ChangingAmerican Academy. New York: State University of New York Press, p. 219.

Krishnan, A. (2009). What are academic disciplines? Some observations on the Disciplinarity vs. Interdisciplinarity Debate. ESRC National Centre for Research Methods. University of Southhampton, p. 63.

Leedy, D., \& Ormrod, J. (2005). Practical Research: Planning and Design ( $8^{\text {th }}$ ed.). Upper Saddle River: NJ. Pearson Education., Inc.

Moran, J. (2010). Interdisciplinarity. New York: Routledge.

National Academy of Sciences, National Academy of Engineering, \& the Institute of Medicine of the National Academies (2015). Facilitating Interdisciplinary Research. Washington, D.C.: USA.

Newell, W.H. (1983). The Case for Interdisciplinary Studies: Response to Professor Benson's Five Arguments. Retrieved from http://www.units.muohio.edu/aisorg/pubs/issues/2_newell.pdf

Newell, W.H. (1992). Academic disciplines and undergraduate interdisciplinary education: Lessons from the Schoolof Interdisciplinary Studies at Miami University, Ohio. European Journal of Education, 27(3), 211-221.

Pickar, A.D. (1970). Core course for science majors combining material from Physics, Chemistry, and Biology. Bioscience, 20, 418-421. http://dx.doi.org/10.2307/1295233

Repko, A.F. (2008). Interdisciplinary Research: Process and Theory. Los Angeles, London, New Delhi and Singapore: Sage.

Repko, A. F. (2006). Disciplining interdisciplinarity: The case for textbooks. Issues in Integrative Studies, 24, $112-142$.

Rhoten, D., BoixMansilla, V., Chun, M., \& Klein, J. T. (2006).Interdisciplinary education at liberal arts institutions. Teagle Foundation White Paper. Retrieved June, 13, 2007.

Salter, L., \& Hearn, A. (1997). Outside the Lines: Issues in Interdisciplinary Research. Montreal: McGill-Queen's Press.

Shailer, K. (2005). Interdisciplinarity in a Disciplinary Universe.COU Colleagues Working Paper. 4(1), 1 - 8.

Strauss, R. (1973). Departments and disciplines: Stasis and change. Science, 182, 895-898. http://dx.doi.org/10.1126/science.182.4115.895

Swora, T., \& Morrison, J.L. (1974). Interdisciplinarity and higher education. Journal of General Education, 26, 45-52.

Weingart, P., \& Stehr, N. (2000). Practising Interdisciplinarity. Toronto: University of Toronto Press.

Wheeler, L., \& Miller, E. (1970). Multidisciplinary Approach to Planning. Paper presented at Council of Education Facilities Planners 47th Annual Conference in Oklahoma City, OK, 6 Oct. 1976. Retrieved from Eric on-line database. 